\title{
Studying the Association between Non Alcoholic Fatty Pancreatic Disease and Non Alcoholic Fatty Liver Disease
}

\author{
Reda M. El-Badawy $^{\mathrm{a}}$, Ahmed F. Yousef ${ }^{\mathrm{b}}$, Hany R. Elkholy ${ }^{\mathrm{a}}$, Ahmed Mustafa ${ }^{\mathrm{c}}$
}

a Department of Hepatology, Gastroentrology and Infectious Diseases, Benha Faculty of Medicine ,Benha university, b Department of Radiology, Benha faculty of Medicine, Benha University, ${ }^{\mathrm{c}}$ Benha fever hospital, Egypt.

Correspondence to: Ahmed Mustafa, Benha fever hospital, Egypt

Email:

sadoma201289@yahoo.com

Received: 28 December 2019

Accepted: 3 February 2020

Abstract:

Background: The pancreas and the liver are organs in which fat is most easily deposited. Nonalcoholic fatty pancreas disease (NAFPD) comprises a wide spectrum of diseases from deposition of fat in the pancreas (fatty pancreas, pancreatic steatosis), to pancreatic inflammation (non-alcoholic steatopancreatitis), pancreatic fibrosis and pancreatic adenocarcinoma. Aim: The aim was to study the association between Non Alcoholic Fatty Pancreas Disease (NAFPD) and Non Alcoholic Fatty Liver Disease (NAFLD). Methods: This study was conducted on 100 subjects (50 patients with sonographically proven NAFLD and 50 normal individuals). Full history taking, clinical examination, routine laboratory and abdominal ultrasound were done. Results: Concurrence of NAFPD and NAFLD on abdominal ultrasound was found in 38/50 patients (76\%). There was statistically significant association of NAFLD with fatty pancreas severity. The present study revealed significant associations of fatty pancreas with aging, obesity, type 2 Diabetes mellitus (T2DM), and dyslipidemia (higher levels of cholesterol, low density lipoprotein (LDL), high density lipoprotein (HDL), very low density lipoprotein (VLDL), triglycerides, cholesterol/HDL (Risk I), LDL/HDL (Risk II).Conclusion: Fatty pancreas is a common finding during medical check-up and has significant association with NAFLD and other metabolic factors. Fatty pancreas could be an initial indicator of ectopic fat deposition and an earlier manifestation of metabolic syndrome than fatty liver.

Key words: Fatty pancreas, Fatty liver, Dyslipidemia.

Abbreviations: NAFPD $=$ Nonalcoholic fatty pancreas disease, NAFLD $=$ Non Alcoholic Fatty Liver Disease, T2DM = Type 2 Diabetes mellitus, LDL = low-density lipoprotein, HDL $=$ high-density Lipoprotein, VLDL $=$ very low density lipoprotein. 



\section{Introduction:}

Non Alcoholic Fatty Liver Disease (NAFLD) is characterized by hepatic triglyceride accumulation not due to alcohol consumption (<20 gram ethanol per day), resulting in steatosis and hepatic inflammation (1). Non Alcoholic Fatty Pancreas Disease (NAFPD) is an excessive lipid accumulation in the pancreas in the absence of significant alcohol intake (2).

NAFPD may allegedly develop into chronic pancreatitis and further leads to pancreatic cancer (3), and facilitates its dissemination (4).The ratio of fatty degeneration in pancreas with pancreatic ductal adenocarcinoma (PDAC) was higher than for pancreas without PDAC (72\% vs. 44\%) (5).

This condition was first described in 1926 (6). Later in 1933 the term 'pancreatic lipomatosis' was used to represent the pathological process of excessive fat storage in the pancreas (7). To date, the pathophysiology of NAFPD remains unclear.

There are two potential mechanisms for pancreatic fat accumulation: (i) death of acinar cells, followed by the replacement of adipose tissue; and (ii) intracellular triglyceride accumulation associated with excessive energy balance (8).

Prevalence of NAFPD has been reported in Asia as well as in western countries. In Taiwan, one study reported that $16 \%$ of Chinese population had fatty pancreas (9) and another study in U.S.A reported that as high as $27.8 \%$ of the patients who underwent endoscopic ultrasound evaluation (EUS) had NAFPD (10).

In Indonesia, which represents the biggest Southeast Asian country, the prevalence of NAFPD in the medical check-up population was $35 \%$ (11).

In Egypt, no studies done till now. Non Alcoholic Fatty Pancreas Disease (NAFPD) is usually an incidental finding during trans-abdominal ultrasound examination. The aim of the study was to determine the association between Non Alcoholic Fatty Pancreas Disease (NAFPD) and Non Alcoholic Fatty Liver Disease (NAFLD).

\section{Subjects and Methods:}

This case control study was conducted on 100 subjects $(\mathbf{5 0}$ patients with sonographically proven NAFLD and $\mathbf{5 0}$ normal individuals) at Hepatology, gastroenterology and infectious diseases department, Faculty of Medicine, Benha University in period from October 2018 to June 2019. Written informed consent was taken from all patients for 
participation in this study and local institutional ethical committee. The studied population was divided as follow:

Group I: Included 50 individuals with sonographically proven NAFLD (18 males and 32 females with mean age $45.64 \pm 9.82$ years)

Group II: Included 50 healthy individuals with no sonographic evidence of NAFLD (18 males and 32 females with mean age 39.42 \pm 10.84 years). All participants were subjected to thorough history taking, full clinical examination including measurement of arterial blood pressure and calculation of the body mass index (BMI), laboratory investigations including complete blood count (CBC), fasting blood glucose, liver biochemical tests including serum alanine aminotransferase (ALT), serum aspartate aminotransferase (AST), total serum bilirubin and direct serum bilirubin, serum albumin, alkaline phosphatase (ALP), gamma-Glutamyl Transpeptidase (GGT), kidney function tests including serum creatinine and blood urea, lipid profile including total cholesterol, low density lipoprotein (LDL), high density lipoprotein (HDL), very low density lipoprotein (VLDL), triglycerides, cholesterol/HDL (Risk I), LDL/HDL
(Risk II) and abdominal ultrasonography for diagnosis of fatty liver, fatty pancreas and grading them by GE healthcare LOGIQ E9 machine. The liver echogenicity was classified into 4 grades (12):

- Grade 0: normal liver echogenicity.

- Grade 1: a slight increase in liver echogenicity with no attenuation in the far field.

- Grade 2: a moderate increase in liver echogenicity with light attenuation in the far field and the diaphragm and vessels clearly visible.

- Grade 3: a substantial increase in liver echogenicity with poor visualization of the diaphragm and the vessels.

NAFLD was diagnosed when the liver appeared as grade 1 to 3 .

The pancreas echogenicity was also classified into 4 grades (13), (14):

- Grade 0: the pancreas echogenicity was similar to the kidney parenchymal.

- Grade 1: pancreas echogenicity was slightly higher than in the kidney, but because the pancreas and kidney could not be displayed in the same screen, the radiologist compared the kidney with the liver and then compared the liver with the pancreas. 
- Grade 2: a substantial increase in pancreas echogenicity but lower than the retroperitoneal fat echogenicity.

- Grade 3: the pancreas echogenicity was similar to or higher than the retroperitoneal fat.

NAFPD was diagnosed when the pancreas appeared as grade 1 to 3 .

\section{Statistical analysis:}

The clinical data were recorded on a report form. These data were tabulated and analyzed using the computer program SPSS (Statistical package for social science) version 20 to obtain: Descriptive data and Analytical statistics.

Descriptive statistics were calculated for the data in the form of:

1. Mean and standard deviation $( \pm S D)$. Median and inter-quartile range (IQR) for quantitative data.

2. Frequency and distribution for qualitative data.

Analytical statistics : In the statistical comparison between the different groups, the significance of difference was tested using one of the following tests:-

1- ANOVA test (F value) and kruskalwallis test:-used to compare mean of more than two groups of quantitative data of parametric and non-parametric respectively.

2- Inter-group comparison of categorical data was performed by using chi square test $\left(X^{2}\right.$-value) and fisher exact test (FET).

$$
\begin{gathered}
x^{2}=\frac{\sum(\text { observed }- \text { expected })^{2}}{\text { Expected }} \\
\text { Expected }=\frac{\text { col.total } x \text { rowtotal }}{\text { Grand total }}
\end{gathered}
$$

A $P$ value $<0.05$ was considered statistically significant $(*)$ while $>0.05$ statistically insignificant Pvalue $<0.01$ was considered highly significant $(* *)$ in all analyses.

\section{Results:}

There was highly statistical significant difference between the studied groups regarding age and body mass index (BMI) Table (1). Mean age and BMI were significantly higher in group I compared to group II Table (1).

There were statistical significant differences between the studied groups regarding HOMA-IR, hemoglobin and platelet count and no statistical significant differences between the studied groups regarding fasting blood sugar, fasting insulin levels and white blood cells (WBCs) count Table (2). HOMA-IR was significantly higher in group I compared to 
group II Table (2). There was no statistical significant difference between the studied groups regarding liver profile except for Gamma-Glutamyl Tranferase GGT with p<0.001 Table (3). GGT levels were significantly higher in group I compared to group II (p <0.001) Table (3).

There were highly statistical significant differences between the studied groups regarding serum triglycerides (TG) and VLDL levels and no statistical significant difference as regards other variables Table (4).

Serum triglycerides and VLDL levels were significantly higher in group I compared to group II Table (4). There was statistical significant difference between the studied groups regarding presence of sonographic evidence of fatty pancreas Table (5).

Fatty pancreas was noted in 38 patients (76.0\%) with NAFLD (group I) compared to 28 healthy individuals (group II) $(56.0 \%)(\mathbf{p}=$ 0.035) Table (5). Also, there was highly statistical significant difference between the studied groups regarding grade III of fatty pancreas. Fatty pancreas grade III was noted in 26 patients $(52.0 \%)$ with NAFLD (group I) compared to 10 healthy individuals (group II) $(20.0 \%)(\mathbf{p}<\mathbf{0 . 0 0 1})$ Table (5).
The two studied groups were subdivided into NAFPD group and non NAFPD group according to presence of sonographic evidence of fatty pancreas. There was no statistically significant difference between the studied groups regarding sociodemographic criteria except for age and BMI Table (6).

There was highly statistical significant difference between the studied groups regarding BMI and statistical significant difference between the studied groups regarding age Table (6). Mean age and BMI were significantly higher in NAFPD group compared to non NAFPD group Table (6).

There was no statistical significant difference between the studied groups regarding liver profile except for GGT with $\mathrm{p}=\mathbf{0 . 0 0 9}$ Table (7). GGT levels were significantly higher in NAFPD group compared to non NAFPD group (p=0.018) Table (7).

There were highly statistical significant differences between the studied groups regarding serum cholesterol, triglycerides, LDL, VLDL levels and cholesterol/HDL ratio, statistical significant difference as regards LDL/HDL ratio and no statistical 
significant difference as regards HDL were significantly higher in NAFPD level Table (8). Serum cholesterol, group compared to non NAFPD group triglycerides, LDL, VLDL levels, Table (8). cholesterol/HDL and LDL/HDL ratios

Table (1): Sociodemographic criteria among the study groups:

\begin{tabular}{|c|c|c|c|c|}
\hline & $\begin{array}{l}\text { Group I (50) } \\
\text { (NAFLD) }\end{array}$ & $\begin{array}{l}\text { Group II (50) } \\
\text { (Non NAFLD) }\end{array}$ & $\begin{array}{l}\text { Statistical } \\
\text { test }\end{array}$ & $P$ value \\
\hline \multicolumn{5}{|l|}{ Sex } \\
\hline Male & $18(36.0 \%)$ & $18(36.0 \%)$ & $\mathrm{FET}=0.0$ & 1.0 \\
\hline Female & $32(64.0 \%)$ & $32(64.0 \%)$ & & \\
\hline Age (year) & $45.64 \pm 9.82$ & $39.42 \pm 10.84$ & St $\mathrm{t}=3.09$ & $0.003 * *$ \\
\hline \multicolumn{5}{|l|}{ Special habits } \\
\hline NO & $42(84.0 \%)$ & $38(76.0 \%)$ & $\mathrm{FET}=3.94$ & 0.17 \\
\hline Smoking & $8(16.0 \%)$ & $8(16.0 \%)$ & & \\
\hline Contraceptive pills & $0(0.0 \%)$ & $4(8.0 \%)$ & & \\
\hline \multicolumn{5}{|l|}{ Residence } \\
\hline Rural & $22(44.0 \%)$ & $38(76.0 \%)$ & $X^{2}=10.67$ & $0.001 * *$ \\
\hline Urban & $28(56.0 \%)$ & $12(24.0 \%)$ & & \\
\hline Weight (kg) & $88.68 \pm 13.74$ & $78.64 \pm 11.01$ & St $\mathrm{t}=4.03$ & $0.001 * *$ \\
\hline Height (cm) & $167.88 \pm 10.15$ & $165.76 \pm 7.9$ & St $\mathrm{t}=1.17$ & 0.25 \\
\hline BMI & $30.5(27.78-35.43)$ & $27.3(25.88-31.25)$ & $M W=3.15$ & $0.002 * *$ \\
\hline Median (IQR) & & & & \\
\hline
\end{tabular}

BMI= Body Mass Index, FET = Fisher exact test, $\mathrm{St} \mathrm{t}=$ Student's $\mathrm{t}$-test, $\mathrm{X}^{2}=$ Chi square test, $\mathrm{MW}=$ MannWhitney $\mathrm{U}$ test, IQR= Inter-quartile range. 
Table (2): Laboratory findings of the study groups:

\begin{tabular}{|c|c|c|c|c|}
\hline & $\begin{array}{l}\text { Group I (50) } \\
\text { (NAFLD) }\end{array}$ & $\begin{array}{l}\text { Group II (50) } \\
\text { (Non NAFLD) }\end{array}$ & $\begin{array}{l}\text { Statistical } \\
\text { test }\end{array}$ & $P$ value \\
\hline FBS (mg/dl) & $89(81.5-123.25)$ & $89(83.75-96.25)$ & $\mathrm{MW}=1.41$ & 0.16 \\
\hline \multicolumn{5}{|l|}{ Median (IQR) } \\
\hline $\begin{array}{l}\text { Fasting insulin } \\
(\mathbf{m I U} / \mathbf{m L})\end{array}$ & $4.59(4.31-5.08)$ & $4.44(4.21-4.84)$ & $\mathrm{MW}=1.16$ & 0.25 \\
\hline \multicolumn{5}{|l|}{ Median (IQR) } \\
\hline HOMA-IR & $1.1(0.98-1.5)$ & $1.0(0.9-1.2)$ & $\mathrm{MW}=2.18$ & $0.03 *$ \\
\hline \multicolumn{5}{|l|}{ Median (IQR) } \\
\hline Hemoglobin (gm/dl) & $13.62 \pm 1.43$ & $12.75 \pm 1.87$ & St $\mathrm{t}=2.64$ & $0.01 *$ \\
\hline WBCs $\left(10^{3} \mathrm{c} / \mathrm{mm}^{3}\right)$ & $6.39 \pm 1.79$ & $6.55 \pm 2.83$ & St $\mathrm{t}=0.33$ & 0.74 \\
\hline Platelets $\left(10^{3} \mathrm{c} / \mathbf{m m}^{3}\right)$ & $224.72 \pm 67.35$ & $263.84 \pm 75.65$ & St $t=2.73$ & $0.007 * *$ \\
\hline
\end{tabular}

HOMA-IR=Homeostatic Model Assessment for Insulin Resistance, WBCs= White blood cells count, St $\mathrm{t}=$ Student's $\mathrm{t}$-test, MW=Mann-Whitney $\mathrm{U}$ test, IQR= Inter-quartile range.

Table (3): Liver profile of the study groups:

\begin{tabular}{|c|c|c|c|c|}
\hline & $\begin{array}{l}\text { Group I (50) } \\
\text { (NAFLD) }\end{array}$ & $\begin{array}{l}\text { Group II (50) } \\
\text { (Non NAFLD) }\end{array}$ & $\begin{array}{l}\text { Statistical } \\
\text { test }\end{array}$ & $P$ value \\
\hline ALT (IU/L) & $16(12-21)$ & $16(13-20.25)$ & $\mathrm{MW}=0.28$ & 0.78 \\
\hline \multicolumn{5}{|l|}{ Median (IQR) } \\
\hline AST (IU/L)(M \pm SD) & $23.88 \pm 6.31$ & $22.24 \pm 6.72$ & St $\mathrm{t}=1.26$ & 0.21 \\
\hline Total bilirubin (mg/dl) & $0.5(0.4-0.6)$ & $0.5(0.4-0.7)$ & $\mathrm{MW}=0.23$ & 0.82 \\
\hline \multicolumn{5}{|l|}{ Median (IQR) } \\
\hline S. albumin (gm/dl) & $5(5-5)$ & $5(4.79-5)$ & $\mathrm{MW}=1.5$ & 0.13 \\
\hline \multicolumn{5}{|l|}{ Median (IQR) } \\
\hline $\operatorname{ALP}(\mathbf{I U} / \mathbf{L})$ & $128.08 \pm 46.11$ & $140.2 \pm 50.31$ & St $\mathrm{t}=1.26$ & 0.21 \\
\hline GGT (IU/L) & $21(17.75-29)$ & $13(9-18)$ & $\mathrm{MW}=5.11$ & $0.001 * *$ \\
\hline Median (IQR) & & & & \\
\hline
\end{tabular}

ALT = Alanine Transaminase, AST $=$ Aspartate Transaminase, ALP= Alkaline Phosphatase, GGT= GammaGlutamyl Tranferase, $\mathrm{St}$ t= Student's $\mathrm{t}$-test, MW=Mann-Whitney U test, IQR= Inter-quartile range. 
Table (4): Lipid profile of the study groups:

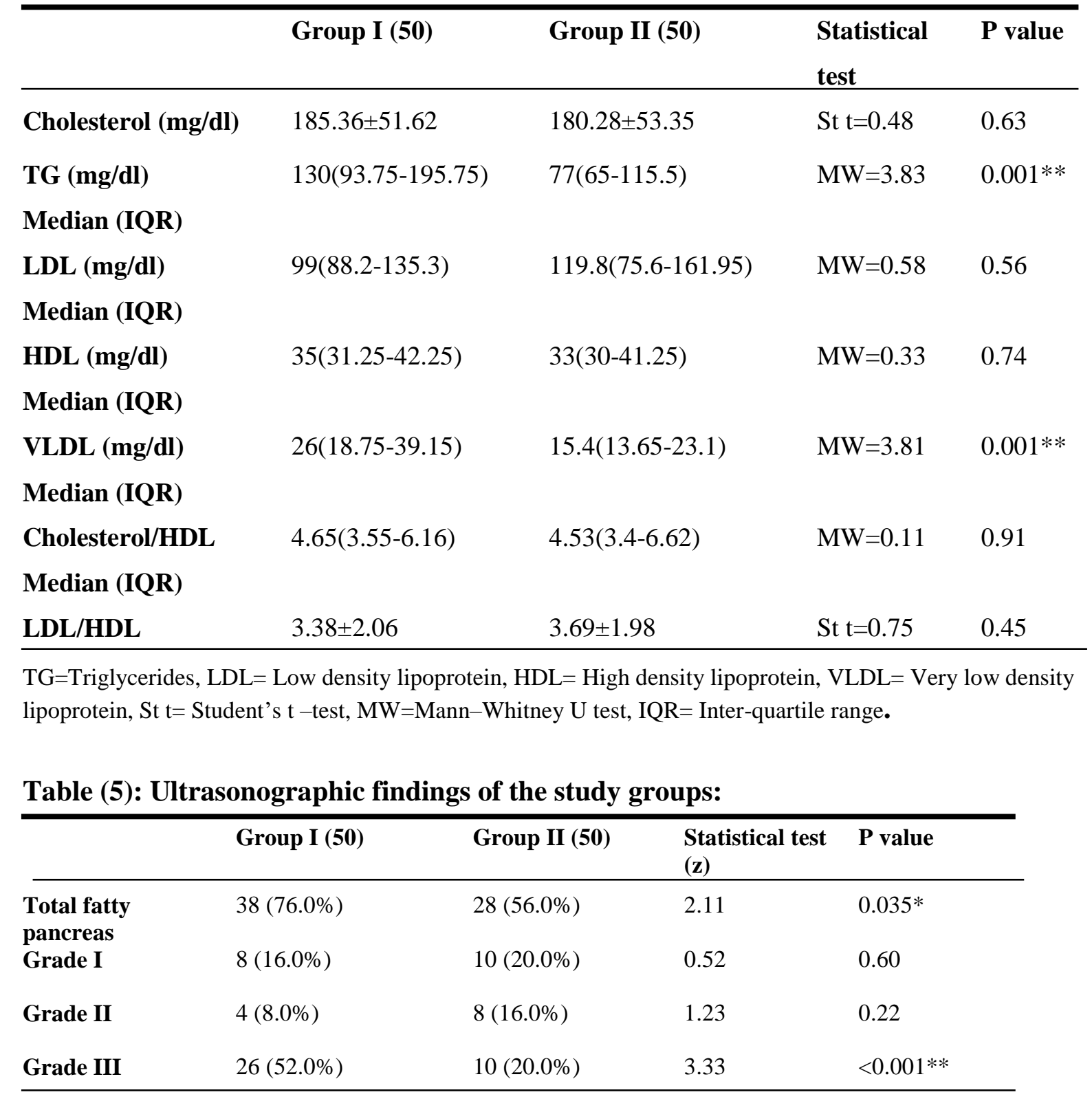


Table (6): Relation between sociodemographic data and NAFPD:

\begin{tabular}{|c|c|c|c|c|}
\hline Total subjects (100) & $\begin{array}{l}\text { NAFPD } \\
(66 / 100) \\
\text { (In both NAFLD \&Non } \\
\text { NAFLD) } \\
\end{array}$ & $\begin{array}{l}\text { Non NAFPD }(34 / 100) \\
\text { (In both NAFLD \&Non } \\
\text { NAFLD) }\end{array}$ & Statistical test & P value \\
\hline \multicolumn{5}{|l|}{ Sex } \\
\hline Male & $24(36.4 \%)$ & $12(35.3 \%)$ & $X^{2}=0.011$ & 0.92 \\
\hline Female & $42(63.6 \%)$ & $22(64.7 \%)$ & & \\
\hline Age (year) & $44.15 \pm 10.24$ & $39.12 \pm 11.17$ & St $\mathrm{t}=2.26$ & $0.026^{*}$ \\
\hline \multicolumn{5}{|l|}{ Special habits } \\
\hline NO & $54(81.8 \%)$ & $26(76.5 \%)$ & $\mathrm{FET}=0.89$ & 0.69 \\
\hline Smoking & $10(15.2 \%)$ & $6(17.6 \%)$ & & \\
\hline Contraceptive pills & $2(3.0 \%)$ & $2(5.9 \%)$ & & \\
\hline \multicolumn{5}{|l|}{ Residence } \\
\hline Rural & $36(54.5 \%)$ & $24(70.6 \%)$ & $X^{2}=2.41$ & 0.12 \\
\hline Urban & $30(45.5 \%)$ & $10(29.4 \%)$ & & \\
\hline BMI & $30.4(27.45-35.65)$ & $27.3(25.88-29.33)$ & $M W=3.64$ & $0.001 * *$ \\
\hline Median (IQR) & & & & \\
\hline
\end{tabular}

BMI= Body Mass Index, FET= Fisher exact test, $\mathrm{St} \mathrm{t}=$ Student's $\mathrm{t}-$ test, $\mathrm{X}^{2}=$ Chi square test, MW=Mann-Whitney $\mathrm{U}$ test, $\mathrm{IQR}=$ Inter-quartile range.

Table (7): Liver profile of the study groups (with \& without NAFPD):

\begin{tabular}{|c|c|c|c|c|}
\hline Group I+II (100) & $\begin{array}{l}\text { NAFPD } \\
(66 / 100) \\
\text { (In both NAFLD } \\
\text { \&Non NAFLD) } \\
\text { 16(13-21.75) }\end{array}$ & $\begin{array}{l}\text { Non NAFPD }(34 / 100) \\
\text { (In both NAFLD \&Non } \\
\text { NAFLD) } \\
16(12.75-17.75)\end{array}$ & $\begin{array}{l}\text { Statistical } \\
\text { test } \\
\text { MW=1.01 }\end{array}$ & $P$ value \\
\hline $\begin{array}{l}\operatorname{ALT}(\text { IU/L) } \\
\text { Median (IQR) } \\
\text { AST (IU/L) }\end{array}$ & $23.76 \pm 7.05$ & $21.71 \pm 5.24$ & $\mathrm{St} \mathrm{t}=1.5$ & 0.14 \\
\hline $\begin{array}{l}\text { T bilirubin (mg/dl) } \\
\text { Median (IQR) }\end{array}$ & $0.5(0.4-0.63)$ & $0.5(0.48-0.63)$ & $\mathrm{MW}=0.68$ & 0.50 \\
\hline $\begin{array}{l}\text { S. albumin (gm/dl) } \\
\text { Median (IQR) }\end{array}$ & $5.0(4.83-5.0)$ & $5.0(5.0-5.0)$ & $\mathrm{MW}=1.79$ & 0.074 \\
\hline $\operatorname{ALP}(\mathbf{I U} / \mathbf{L})$ & $136.94 \pm 45.27$ & $128.71 \pm 54.26$ & St $\mathrm{t}=0.80$ & 0.42 \\
\hline $\begin{array}{l}\text { GGT (IU/L) } \\
\text { Median (IQR) }\end{array}$ & $19(13.75-24.5)$ & $14(11.25-21.25)$ & $\mathrm{MW}=2.61$ & $0.009^{* *}$ \\
\hline
\end{tabular}


Table (8): Lipid profile of the study groups (with \& without NAFPD):

\begin{tabular}{|c|c|c|c|c|}
\hline Group I+II (100) & $\begin{array}{l}\text { NAFPD } \\
(66 / 100) \\
\text { (In both NAFLD } \\
\text { \&Non NAFLD) } \\
\end{array}$ & $\begin{array}{l}\text { Non NAFPD }(34 / 100) \\
\text { (In both NAFLD \&Non } \\
\text { NAFLD) }\end{array}$ & Statistical & P value \\
\hline Cholesterol (mg/dl) & $195.21 \pm 51.92$ & $158.76 \pm 44.62$ & St $\mathrm{t}=3.48$ & $0.001 * *$ \\
\hline $\begin{array}{l}\text { TG }(\mathrm{mg} / \mathrm{dl}) \\
\text { Median (IQR) }\end{array}$ & $123(93.75-180.25)$ & $71(59-100.5)$ & $\mathrm{MW}=4.34$ & $0.001 * *$ \\
\hline $\begin{array}{l}\text { LDL (mg/dl) } \\
\text { Median (IQR) }\end{array}$ & $119.8(90.05-169.6)$ & $97.5(75.85-126.5)$ & $\mathrm{MW}=2.49$ & $0.001 * *$ \\
\hline $\begin{array}{l}\text { HDL (mg/dl) } \\
\text { Median (IQR) }\end{array}$ & $34(29.75-42.25)$ & $35(31.75-41.25)$ & $\mathrm{MW}=0.85$ & 0.40 \\
\hline $\begin{array}{l}\text { VLDL (mg/dl) } \\
\text { Median (IQR) }\end{array}$ & $24.6(18.75-36.05)$ & $14.2(12.1-20.1)$ & $\mathrm{MW}=4.22$ & $0.001 * *$ \\
\hline $\begin{array}{l}\text { Cholesterol/HDL } \\
\text { Median (IQR) }\end{array}$ & $5.31(4.11-6.8)$ & $3.8(3.37-5.58)$ & $\mathrm{MW}=2.71$ & $0.007 * *$ \\
\hline LDL/HDL & $3.86 \pm 2.26$ & $2.9 \pm 1.22$ & St $\mathrm{t}=2.29$ & $0.024 *$ \\
\hline
\end{tabular}

TG=Triglycerides, $\mathrm{LDL}=$ Low density lipoprotein, $\mathrm{HDL}=$ High density lipoprotein, VLDL= Very low density lipoprotein, St t= Student's t -test, MW=Mann-Whitney U test, IQR= Inter-quartile range.

\section{Discussion:}

The pancreas and the liver are organs in which fat is most easily deposited (15). It has been reported a prevalence of NAFPD $(16 \%)$ in the general adults with an increase of this percentage in obese subjects with fatty liver (9). In the current study, concurrence of NAFPD and NAFLD on abdominal ultrasound was found in 38 of 50 patients $(76 \%)$.

It has been reported a prevalence of fatty pancreas at ultrasound examination in about $50 \%$ of adults with biopsy-proven Non Alcoholic Steatohepatitis (NASH) (16), while another study in children reported that prevalence of fatty pancreas in approximately half of children with NAFLD, and this percentage was of about $80 \%$ in patients with biopsy-proven NASH (17). Another study showed that about $68 \%$ of cases with fatty pancreas concurrently had fatty liver, but most subjects (97\%) with fatty liver had fatty pancreas (18).

The positive predictive value of fatty liver in fatty pancreas was around $70 \%$, but the negative predictive value of fatty liver in normal pancreas was high to $96 \%$ (18). These findings suggested that fatty pancreas could be an initial indicator of ectopic fat deposition and an earlier manifestation of metabolic syndrome than fatty liver (18). It has been reported that approximately $71.7 \% \quad(38 / 53)$ of the 
subjects with fatty pancreas also had fatty liver disease, while the proportion of subjects with fatty pancreas among individuals with fatty liver disease was merely $10.5 \%$ (38/363) (15).

Fatty liver disease was significantly associated with fatty pancreas $(\mathrm{p}<0.05)$, confirming previous studies based on ultrasound (US) (19) and magnetic resonance imaging (MRI) (20). Furthermore, findings of EUS studies showed an association of fatty pancreas with hepatic steatosis (10), and findings of one MRI study revealed a correlation of pancreatic fat content with liver fat content (20). In contrast, no association between pancreatic fat and liver fat was found in other MRI studies (21).

The findings of one autopsy study demonstrated that total pancreatic fat is significantly correlated with NAFLD (22). In the current study, among the 66 subjects who showed fatty pancreas, 18 patients were found to have mild fatty pancreas (grade I ), 12 moderate fatty pancreas (grade II ), and 36 severe fatty pancreas (grade III ). Sever fatty pancreas was noted in 26 patients $(52.0 \%)$ with NAFLD (group I) compared to 10 healthy individuals $($ group II $) \quad(20.0 \%) \quad(\mathbf{p} \quad<0.001)$ demonstrating statistically significant correlation of NAFLD with fatty pancreas severity.

In the current study, the mean age of patients with NAFPD was $(44.15 \pm 10.24)$ years which was significantly higher compared to non NAFPD subjects $(39.12 \pm 11.17)$. This result agreed with a study which reported that the prevalence of NAFPD is more frequent with increasing age (23). Fatty replacement on pancreas was an inevitable aging process (24).

Other studies using cut off of 60 year-old age (25) and 35 year-old age (11) also showed an association of NAFPD with age. It has been reported that presence of fatty pancreas was significantly associated with age >35 years (11). This also came in agreement with a result of study which showed a positive correlation between age and fatty pancreas, with increasing prevalence of fatty pancreas with age (15). Therefore, older age is considered as an important risk factor of NAFPD. This might be related to lipid metabolism dysfunction being aggravated by agerelated slowing of metabolism and aggravation of ectopic fat deposition caused by prolonged dyslipidemia (26).

On the contrary to the previous studies (11) (25), our study showed no association of 
male gender and NAFPD. It was hypothesized that men are at higher risk to develop NAFPD because they had more visceral (abdominal) fat deposition while women had more subcutaneous (glutealfemoral) lipid deposition (25)(27).

Our data showed that as compared to the absence of fatty pancreas, the presence of the disease was associated with higher values of BMI. In the fatty pancreas group to compared non-fatty pancreas group, the mean body mass index (30.4(27.45-35.65) kg/m2 vs. 27.3 (25.88-29.33) kg/m2, P < 0.001) was statistically higher (18). This result came in agreement with the study which showed that the proportions of subjects with central obesity and BMI $>24$ $\mathrm{kg} / \mathrm{m} 2$ were significantly higher in the FP group than those in the non-FP group (90.6\% vs. $43.9 \%$ and $28.3 \%$ vs. $11.7 \%$, respectively) (15). Available studies have also reported an association between BMI and fatty pancreas (9) (11) (18).

The present study revealed that fatty pancreas and normal pancreas groups did not differ with respect to liver function except for $\gamma$-glutamyltranspeptidase $(\gamma \mathrm{GT})$ values. $\quad \gamma$-glutamyltranspeptidase $(\gamma \mathrm{GT})$ levels (19(13.75-24.5) vs 14(11.25-21.25), $P=0.009)$ showed significant differences between the two groups. In a previous trans-abdominal ultrasonographic study, it has been reported a correlation between fatty pancreas and liver enzymes including AST, ALT, and $\gamma \mathrm{GGT}$ (18). In contrast, another study showed that no significant associations were found between fatty pancreas and AST, ALT, and $\gamma$ GGT levels (15).

As compared to the normal pancreas group, the fatty pancreas group was characterized by a significantly higher total cholesterol $(195.21 \pm 51.92$ vs $158.76 \pm 44.62, P=$ 0.001), TG (123(93.75-180.25) vs71(59100.5), $P<0.001)$, LDL-C (119.8(90.05169.6) vs 97.5(75.85-126.5), $P<0.001)$, and VLDL-C values (24.6(18.75-36.05) vs14.2(12.1-20.1), $P<0.001)$ and by a significantly higher Cholesterol/HDL (5.31(4.11-6.8) vs 3.8(3.37-5.58), $P=$ $0.007)$ and $\mathrm{LDL} / \mathrm{HDL}$ ratios $(3.86 \pm 2.26$ $v$ s.9 $\pm 1.22, P=0.024)$. By contrast, no differences in HDL-C values between the two groups were observed. Available study has reported that fatty pancreas was associated with higher levels of total cholesterol, triglycerides and high density lipoprotein cholesterol than the control group (18).

In the present study there were statistically significant associations between NAFLD 
group and components of metabolic syndrome (MetS) including aging, obesity, type 2 Diabetes mellitus (T2DM), and dyslipidemia. In agreement of our results, fatty liver was reported to be associated with insulin resistance, dyslipidemia, and obesity and is therefore considered a phenotype of metabolic syndrome (28). The present study revealed significant associations of fatty pancreas with aging, obesity, T2DM, and dyslipidemia and association between NAFPD and NAFLD . Finally, Our findings indicated that NAFPD and NAFLD may had the same risk factors leading to fat accumulation in both organs such as obesity, dyslipidemia and diabetes, so that control of these risk factors decreases the incidence of both diseases.

\section{Conclusion:}

Pancreatic fat should not be considered an inert accumulation of fat. The present study suggests that fatty pancreas could be an initial indicator of ectopic fat deposition and an earlier manifestation of metabolic syndrome than fatty liver. Further study about the long standing condition of fatty pancreas will be needed to detect it's progression.

\section{Acknowledgment:}

Thanks to Benha University for funding the project (Fatty liver Among Employees at Benha University) as the thesis is part from it.

\section{References:}

1. Tarantino G. , Savastano S., Colao A. (2010): Hepatic steatosis, low-grade chronic inflammation and hormone/growth factor/adipokine imbalance. World J Gastroenterol. 2010;16:4773-83.

2. Alempijevic T, Dragasevic S, Zec S, Popovic D, Milosavljevic T. (2017): Nonalcoholic fatty pancreas disease. Postgrad Med J; 93:226-230.

3. Hori M, Takahashi M, Hiraoka N, Yamaji T, Mutoh M, Ishigamori R, et al. (2014): Association of Pancreatic Fatty Infiltration With Pancreatic Ductal Adenocarcinoma. ClinTranslGastroenterol; 5:1-5.

4. Mathur A, Zyromski NJ, Pitt HA, Al-Azzawi H, Walker JJ, Saxena R, et al. (2009): Pancreatic steatosis promotes dissemination and lethality of pancreatic cancer. J Am CollSurg; 208:989-96.

5. Tomita Y, Azuma K, Nonaka Y, Kamada Y, Tomoeda M, Kishida M, et al.(2014):Pancreatic fatty degeneration and fibrosis as predisposing factors for the development of pancreatic ductal adenocarcinoma. Pancreas; 43:1032-41.

6. Schaefer JH. (1926): The normal weight of the pancreas in the adult human being: A biometric study. Anat Rec.;32(2): 119-32.

7. Ogilvie RF. (1933):The islands of langerhans in 19 cases of obesity.JPatholBacteriol; 37: 473481. 
8. Smits MM, van Geenen EJ. (2011):The clinical significance of pancreatic steatosis. Nat Rev GastroenterolHepatol; 8:169-177.

9. Wang CY, Ou HY, Chen MF, Chang TC, Chang CJ. (2014): Enigmatic ectopic fat: prevalence of nonalcoholic fatty pancreas disease and its associated factors in a Chinese population. J Am Heart Assoc; 3:297-304.

10. Sepe PS, Ohri A, Sanaka S, Berzin TM, Sekhon S, Bennett G, et al. (2011):prospective evaluation of fatty pancreas by using EUS. GastrointestEndosc; 73:987-93.

11.Lesmana CR, Pakasi LS, Inggriani S, Aidawati ML, Lesmana LA. (2015): Prevalence of nonalcoholic fatty pancreas disease (NAFPD) and its risk factors among adult medical check-up patients in a private hospital: a large cross sectional study. BMC Gastroenterol; 15:1-5.

12. Ahn JM, Paik YH, Min SY, Cho JY, Sohn W, Sinn DH, et al. (2016): Relationship between controlled attenuation parameter and hepatic steatosis as assessed by ultrasound in alcoholic or nonalcoholic fatty liver disease. Gut Liver 2016;10: 295-302.

13. Lee JS, Kim SH, Jun DW, Han JH, Jang EC, Park JY, et al. (2009): Clinical implications of fatty pancreas: correlations between fatty pancreas and metabolic syndrome. World $\mathbf{J}$ Gastroenterol 2009;15: 1869-1875.

14. Marks WM, Filly RA, Callen PW.(1980): Ultrasonic evaluation of normal pancreatic echogenicity and its relationship to fat deposition. Radiology 1980; 137:475-9.

15.Dan Wang, Xiao-ping Yu, Wei-ming, Xiu-ping Jiao, Jian Wu, Dong-ling Teng, et al. (2018): Prevalence and clinical characteristics of fatty pancreas in Yangzhou,China: A cross sectional study Pancreatology 18 (2018) 263-268.

16. Uygun A, Kadayifci A, Demirci H, Saglam M, Sakin YS, Ozturk K, et al. (2015): The effect of fatty pancreas on serum glucose parameters in patients with nonalcoholic steatohepatitis. Eur J Intern Med 2015; 26: 37-41.

17.Della Corte C, Mosca A, Majo F, Lucidi V, Panera N, Giglioni E, et al. (2015): Nonalcoholic fatty pancreas disease and Nonalcoholic fatty liver disease: more than ectopic fat. ClinEndocrinol (Oxf) 2015; 83: 656-662.

18. Lee JS, Kim SH, Jun DW, Han JH, Jang EC, Park JY,et al. (2009): Clinical implications of fatty pancreas: correlations between fatty pancreas and metabolic syndrome. World $\mathbf{J}$ Gastroenterol 2009;15: 1869-1875.

19.Wu WC, Wang CY .(2013): Association between non-alcoholic fatty pancreatic disease (NAFPD) and the metabolic syndrome: casecontrol retrospective study. CardiovascDiabetol 2013; $12: 77$.

20.Sijens PE, Edens MA, Bakker SJ, Stolk RP (2010): MRI-determined fat content ofhuman liver, pancreas and kidney. World J Gastroenterol 2010,16(16):1993-1998.

21.Heni M, Machann J, Staiger H, Schwenzer NF, Peter A, Schick F, et al. (2010): Pancreatic fat is negatively associatedwith insulin secretion in individuals with impaired fasting glucose and/orimpaired glucose tolerance: a nuclear magnetic resonance study.DiabetesMetab Res Rev 2010, 26(3):200-205.

22. van Geenen EJ, Smits MM, Schreuder TC, van der Peet DL, BloemenaE,Mulder CJ (2010): Nonalcoholic fatty liver disease is related to 

nonalcoholic fattypancreas disease. Pancreas 2010, 39(8):1185-1190.

23.Juliyanti $\mathrm{Fu}$, C Rinaldi A Lesmana, Imam Subekti, Irsan Hasan, Andri Sanityoso, Kuntjoro Harimurti, et al. (2017): NonAlcoholic Fatty Pancreas Disease and its Associated Factors in Type 2 Diabetes Mellitus Patients JOP. Journal of the Pancreas Vol. 18 No. 5 -Sep 2017. [ISSN 1590-8577].

24. Tariq H, Nayudu S, Akella S, Glandt M, Chilimuri S.(2016):Non Alcoholic Fatty Pancreatic Disease: A Review of Literature. Gastroenterol Res 2016; 9:87-91. [PMID: 28058076]

25. Choi CW, Kim GH, Kang DH, Kim HW, Kim DU, Heo J, et al. (2010): Associated factors for a hyperechogenic pancreas on endoscopic ultrasound. World J Gastroenterol 2010; 16:4329-34. [PMID: 20818817]

26. Wallace TM, Levy JC, Matthews DR. (2004): An increase in insulin sensitivity and basal beta-cell function in diabetic subjects treated with pioglitazone in a placebo-controlled randomized study. Diabet Med 2004;21:56876.

27. Blaak E. (2001): Gender differences in fat metabolism. CurrOpinClinNutrMetab Care 2001; 4:499-502. [PMID: 11706283]

28. Park BJ, Kim YJ, Kim DH, Kim W, Jung YJ, Yoon JH, et al. (2008): Visceral adipose tissue area is an independent risk factor for hepatic steatosis. J GastroenterolHepatol 2008, 23(6):900-907

To cite this article: Reda M. El-Badawy, Ahmed F. Yousef, Hany R. Elkholy, Ahmed Mustafa. Studying the Association between Non Alcoholic Fatty Pancreatic Disease and Non Alcoholic Fatty Liver Disease. BMFJ,2020; 37(2):391-405. DOI:10.21608/bmfj.2020.21491.1198 
Original article 